\title{
2006-1835: STUDENT COMPETITIONS - THE BENEFITS AND CHALLENGES
}

\section{Peter Schuster, California Polytechnic State University}

Peter Schuster is interested in automotive safety, impact, biomechanics, finite element analysis, and design. He earned a Physics BA from Cornell University, MSME in design from Stanford University, and Ph.D. in biomechanics from Michigan Technological University. After ten years in body design and automotive safety at Ford Motor Company he joined the Mechanical Engineering department at Cal Poly. He teaches mechanics, design, stress analysis, and finite element analysis courses and serves as co-advisor to the student SAE chapter.

\section{Andrew Davol, California Polytechnic State University}

Andrew Davol graduated with a BSME from the California Polytechnic State University, San Luis Obispo (Cal Poly), in 1987. He worked for Boeing Commercial Aircraft Company as a designer and stress analyst before completing a $\mathrm{Ph}$.D. in structural engineering at the University of California, San Diego, in 1998. Andrew is currently an associate professor in Mechanical Engineering at Cal Poly specializing in mechanics. He has advised the ASME sponsored Human Powered Vehicle Club for 5 years.

\section{Joseph Mello, California Polytechnic State University}

Joseph Mello received bachelor and master degrees from California Polytechnic State University San Luis Obispo. He earned a Ph.D. at University of California at Davis in 1996. Dr. Mello has compiled over ten years of industrial experience in the areas of machine design, structural mechanics, and reinforced materials. Dr. Mello is now a Professor in Mechanical Engineering at Cal Poly San Luis Obispo. He teaches primarily mechanical design and has done development and applied research in the areas of design, finite element analysis, and composite materials over the past eight years. He has been advisor and co-advisor of the Cal Poly SAE chapter since 2000. 


\title{
Student Competitions - The Benefits and Challenges
}

\begin{abstract}
Intercollegiate design competitions are a popular means to engage students in design activities that extend beyond the curriculum. When students gather around a project in their spare time and use their classroom skills to design, build, and test a product for an intercollegiate competition, something amazing happens: They develop a passion for engineering. This paper discusses the key benefits to engineering undergraduate students that flow from involvement in a team design competition. Advisor involvement plays a key role in both project success and student learning throughout the process. Different approaches to advising student competition teams are compared. Specific examples are taken from the authors experience with Formula SAE, SAE Mini Baja, and ASME's Human Powered Vehicle competitions.

Responsibility for making the most effective educational use of a design competition is shared between the students, the faculty advisor, and the competition organizers. Design competitions build student enthusiasm; however, there are some things they learn that we may not want to be teaching. Some of the educational shortcomings of these activities are highlighted, with suggestions on how to manage them. In particular, this article focuses on the risks of (a) distraction from classes, (b) a build-and-test approach, (c) advisor co-opted designs, and (d) design changes for their own sake. The influence of the advisor and the competition rules on each of these concerns will be discussed. Finally, the competitions themselves will be investigated to see how the form of the events may be improved to further enhance the learning opportunities for the students.
\end{abstract}

\section{Introduction}

Engineers seem to thrive on competition. At least, that is the perception you would gain if you looked at the student clubs on our campus. The Society of Automotive Engineers (SAE) club will develop and race vehicles in the Formula SAE, Mini Baja, and Supermileage competitions this year. The American Society of Mechanical Engineers' (ASME) Human Powered Vehicle (HPV) team has developed winning vehicles in that competition for three years running. The American Society of Heating, Refrigeration, and Air-Conditioning Engineers (ASHRAE) worked on the Solar Decathalon project. Students in our department also have a Robotics club and a hybrid vehicle club.

As faculty at a primarily undergraduate institution (PUI), we are interested in identifying and supporting those student activities that contribute most directly to student learning. However, as with most PUI's, our school has high teaching loads and an increasing focus on research for professional development. The time we have available to devote to student clubs is limited, so we want to ensure we make the most of it.

In this paper, we discuss the benefits and issues of various intercollegiate design competitions, focusing on those directly within our experience - ASME HPV, Formula SAE, SAE Mini Baja, and SAE Supermileage. The authors all teach design and mechanics classes and are advisors of these four vehicle teams. Based on the authors' different advising approaches - and observations 
of advisors at other schools - a set of best practices is identified to improve the learning experience. In addition, specific issues we have experienced with each of the listed competitions will provide a basis for a set of suggested improvements for intercollegiate design competitions in general.

These competitions operate on a one-year development cycle. During that time, the team is expected to design, analyze, built, test, and prepare reports on the project. Most competitions require an all-new or mostly-new vehicle each year. A typical timetable is:

- Early summer (after the prior year's competition), the design rules for the competition are updated - meaning only limited vehicle development can take place before this point.

- Design and analysis typically takes place during the late summer and fall.

- Procurement, fabrication, and assembly typically fill the winter.

- Testing and redevelopment of the vehicle take place in the weeks before competition.

- The competition takes place in the spring or early summer.

\section{Benefits of student competitions}

Student design competitions are a fantastic experience for students. Good designers have real experience and confidence that can only come from designing, building, and testing real hardware. The SAE competitions are particularly good in that they provide opportunities for students to design machines they are passionate about. This group is very motivated as a result.

Students involved in a design build competition gain many advantages over their classmates that are difficult to quantify, although many papers have captured student perceived benefits from observations and surveys ${ }^{2,8}$. The experience of going through a design, build, and test cycle under a strict time schedule with well defined design goals gives these students more of a "real world" engineering experience than they get through their standard course work. These students get a first hand sense of the importance of:

- Following a schedule,

- Communication and coordination,

- Designing to a budget,

- Manufacturability concerns,

- Lead times for ordering materials, and

- Thorough documentation.

Of course the increased personal fabrication skills often gained also make these students attractive to employers who value engineers with a greater understanding of the complete product cycle.

Often students involved in competition design projects find themselves reaching forward into the curriculum for analysis tools that they need to accomplish their design tasks. This reaching builds life long learning skills that are difficult to get in the standard classroom environment.

Students involved in club activities are never at a loss for project ideas in classes that require student-initiated projects. For example, our senior technical elective on finite element analysis 
has a lab component that requires the students to perform an analysis on a structure of their own choosing. Students involved in building a vehicle are often choosing from a wide range of projects that apply to their club activities whereas many other students are at a loss to come up with a project that interests them.

Design competitions also provide benefits to the faculty advisors. Close involvement with a group of students in an informal setting improves a professor's ability to understand and identify with the student body as a whole. Working with the challenges of a major new design project keeps us active in the field. The students are always trying to push the envelope, and look for the advisor's help to achieve this.

The department and college also benefit from student design competitions. Student teams performing well at the competition bring recognition to their school. Since their experiences have increased their bond with the school, students often become active, contributing alumni after graduation. Design projects are a real draw to prospective new students, and can help the school attract the best and brightest.

\section{Educational risks seen in current competitions}

There are many challenges or issues for students working on vehicles for these design competitions. Table 1 provides a list of issues or problems that have been observed with the typical extracurricular "student driven" approach. Possible causes are listed for each issue.

The educational risks all relate to what the students learn about the design process. Since the goal of these competitions is to give students experience with that process (to a degree not often possible in the classroom), it is unfortunate that the competitions themselves can lead to a misunderstanding of how to use design. Because of time, experience, and competition rules, the students will often not perform an adequate design before moving on to construction. This results in sub-optimal vehicles with recurring problems, and limits performance at competition.

The student issues mostly relate to time management. This becomes a critical issue for students involved in a competition. As deadlines approach the tendency for many students is to let their class work slip and focus too much of their effort on the competition. To some degree a good student weighs the costs and benefits and makes rational decisions as too how much effort he/she can afford to put into the club project. This type of student may sacrifice an " $A$ " in a course or two for their participation in a club project, knowing that the experience they are gaining may well outweigh a small difference in GPA when they are interviewing for a job. However, at the other end of the spectrum is a student who loses focus and allows the competition to become totally consuming. Good advising and project planning can go a long way to avoid this problem but sometimes it is extremely difficult to keep students focused on class work when the adrenaline of competition is so much more compelling.

Technical issues as well relate primarily to resource (funding, time, people) availability. This is common in industry as well and can provide a good learning experience for the students, but only if properly advised. In particular, if the constraints are too severe, the results may be only disillusionment and frustration. It is up to the advisor to see where that line is. 
Table 1: Summary of major issues identified

\begin{tabular}{|c|c|}
\hline Issue & Possible Causes \\
\hline \multicolumn{2}{|r|}{ Education } \\
\hline Design changes for their own sake & $\begin{array}{l}\text { - New team members want to 'make their mark' } \\
\text { - Design rules require new components }\end{array}$ \\
\hline $\begin{array}{l}\text { All innovation, no incremental } \\
\text { improvements }\end{array}$ & $\begin{array}{l}\text { - Insufficient time to analyze failures and identify } \\
\text { improvements } \\
\text { - } \\
\text { - } \quad \text { Tesign rules require new components want to test new ideas }\end{array}$ \\
\hline Skip design, just build \& test & $\begin{array}{ll}\text { - } & \text { Inadequate knowledge to properly design } \\
\text { - } & \text { Previous 'tinkering' experience highly valued } \\
\text { - } & \text { Competition rules and funding limitations force } \\
& \text { teams to manufacture most components }\end{array}$ \\
\hline \multicolumn{2}{|r|}{ Student } \\
\hline Safety, both in shop and travel & $\begin{array}{ll}\text { - } & \text { Lack of supervision } \\
\text { - } & \text { Inadequate support equipment }\end{array}$ \\
\hline Poor academic performance & $\begin{array}{l}\text { - Inadequate team size } \\
\text { - } \quad \text { Missing school because of travel to competition } \\
\text { - } \quad \text { No academic credit for project }\end{array}$ \\
\hline $\begin{array}{l}\text { Embarrassed, disappointed, sad } \\
\text { students }\end{array}$ & $\begin{array}{ll} & \text { Failure at competition } \\
\text { - } & \text { Poor management skills, people "driven off" } \\
\end{array}$ \\
\hline \multicolumn{2}{|r|}{ Technical } \\
\hline $\begin{array}{l}\text { Incomplete or partially engineered } \\
\text { vehicles }\end{array}$ & $\begin{array}{l}\text { - Lack of experience, technically emotionally } \\
\text { - Too much to do (scope) } \\
\text { - Lack of real intermediate project milestones }\end{array}$ \\
\hline Poorly designed vehicles & - No experience with setting schedule scope \\
\hline Poor quality fabrication & $\begin{array}{l}\text { - } \quad \text { Minimal or no advising and training. } \\
\text { - } \quad \text { Trying to go too fast, take short cuts } \\
\text { - Inadequate funds } \\
\text { - Inadequate shop hours }\end{array}$ \\
\hline $\begin{array}{l}\text { Inadequate design reports / cost } \\
\text { reports / presentations }\end{array}$ & $\begin{array}{l}\text { - No history of past vehicles - successes, failures } \\
\text { - No time to prepare reports and presentations - all } \\
\text { time spent constructing }\end{array}$ \\
\hline
\end{tabular}

\section{Influence of advisor involvement}

To optimize the learning experience for the students it is imperative to have an involved advisor (or several). Many of the lessons learned by the students mentioned in this paper will occur with or without this involvement, and the students may even have some success on their own. But the 
likelihood of a successful competition goes up markedly if the students are guided and feel that their advisor(s) is genuinely interested in the project $\mathrm{t}^{3,7}$.

In recent years, our clubs have received increased attention from the faculty advisors. This increase has manifested itself most notably in the design documentation that the teams have submitted to their competitions. The ASME HPV team has been very competitive for several decades in the performance events. But more than once in the recent past no design documentation was submitted; and often if documentation was submitted it was well below par for the competition. This team has not lost a sprint race in over five years and is usually one of the top, if not the top, finisher in the road race. However the lack of attention to the design documentation kept them from being a top competitor for the overall title. The current attention to details, such as the design documentation, has significantly improved the team's standing.

Of course an advisor can become too involved in the design as well. There is a level of advisor involvement where the project ceases to be truly run by the students and the advisor becomes the chief engineer. This ensures specific experiences but in a sense the team is less empowered. One way to avoid this risk is to leave the design decision-making to the students. Then, the advisor's role can be to support the project planning and technical development (as a consultant).

How best to have an advisor involved in the project? With increasing demands on our time, how is a faculty advisor to allocate his energy most effectively? Here are a few alternatives:

\section{Integrate into Curriculum}

Many schools integrate these competitions into their course work, often by tackling the project with their senior design class 5 . Other schools run the teams totally outside of the curriculum and count on student motivation to keep the projects going within their individual clubs. There are advantages and disadvantages to both of these models.

The senior design class has the advantage of having a large pool of senior engineering students complete with all of the analytical and design skills commensurate with their class level. These teams are very well equipped to do good design work with complete analysis and documentation but may not do so well in project planning and manufacturing since the students only go through the project cycle once. In addition, this approach can partially address the student time management issue. Since the students will receive course credit for their project work, they have less other coursework to focus on. The course instructor can also impose additional time management discipline on the project as part of the course schedule. Another benefit this model provides is teaching credit for the advisor. The senior design class instructor will provide technical guidance to the design team as part of a normal teaching load (rather than overhead, as club advising usually is). Whether or not the advisor is the instructor, this frees up some of the club advisor's time to focus on other club activities. There are some negatives to this approach, however. Bringing the efforts into the classroom seems to result in the advisor taking more of a lead because of the roles of student and professor. This does help as there is more organized engineering, but it also detract from the unique experience where the students are in charge. In addition, historically, seniors become less active in the clubs; perhaps because they have already completed the desired experience, or because they now understand that they need to focus on 
their classes to get a job! The result may be that those less interested in the result do the development.

The club approach is much more conducive to continuity as some students may join as freshmen and stay on the team throughout their undergraduate career. This model leads to a great increase in fabrication skills and total understanding of the necessary effort to put together a complete project. The downside is that there is no guarantee that the team will have a substantial number of upperclassmen capable of doing the higher level of analysis necessary to put together a really good design. Without careful attention the teams can swell and shrink in cycles that may leave them with no upperclassmen to lead the design effort.

This year we have started to implement a hybrid version of these two models, similar to that being implemented at a few other universities 9 . This hybrid model leaves the management of the project in the hands of a club whose membership represents all levels of the student population. However, the team can use senior design class to take on specific subsystems required for the overall project. For example, in this year's Mini-Baja vehicle, the club officers and members made the global layout and high-level design decisions. Then, students in the senior design class took on subsystem design projects that included a new continuously variable transmission, front and rear suspension, and steering system. The ASME HPV team also had four teams working through the senior design class on various subsystems. As this hybrid model is brand new to us we have no competition results to point to but at the time of submittal both the Baja and HPV teams seem well ahead of schedule compared to recent efforts.

It is interesting to note that there are other models used at different universities. For example, project work can be performed in dedicated classes focused year-round on preparing a vehicle for competition ${ }^{5,6}$. In other cases, the senior project model can be a full-year class where the club advisor acts as the engineering team leader, hand-picking a team to work on the project ${ }^{7}$. Another option involves giving small amounts of course credit over a number of years while the student is participating in the project, either through specific project courses ${ }^{4}$, or as assigned projects in a number of different courses ${ }^{1}$.

\section{Address Systemic Problems}

Many issues experienced by the teams occur year after year despite an advisor's best efforts. In order to address these systemic problems, institutional changes may be required. While making these changes may take additional time in the short term, the benefits should be felt for years afterwards. In this section we will discuss a few of the changes we have tried or considered, and their anticipated effects.

$\underline{\text { Safety First }}$ - Construction and testing of the vehicles, and traveling to competition are the three most dangerous club activities. Before any educational concerns, the primary focus of the advisor must be student safety. Our department is fortunate to have a large, well-equipped, supervised student shop to reduce the risk of injuries during construction. Testing is conducted following strict rules and only with pre-approval of campus authorities. The SAE group was able to get the donation of a new trailer and then with department and student funding support a new van was purchased. The competition travel is much safer as a result. There still are safety challenges associated with driving such a large vehicle and trailer. Training has been established 
within the department, but there is still a worry about tired students who have been working late to finish a vehicle. This time problem needs to be addressed for safe travel.

Project Planning - Advisors can contribute immeasurably to project planning. Although students will get the most experience out of developing their own detailed timetables, the advisor has the experience to ensure these are reasonable. Last year, we were faced with this decision on the Formula SAE project. The team proposed an innovative formula design that went away from the past several years of experience. Given the resources, we mandated a two-year design effort. Although missing a year of Formula competition upset some students, others privately thanked us for relieving the pressure. The experiment has had mixed results so far. The car is the most completely engineered car in recent memory. But the push has not been hard enough and much of the additional time has been squandered as a result. The final manufacturing and assembly time is similar to the past.

In addition to ensuring reasonability, the advisor can enforce specific critical dates (intermediate milestones) on the overall process. As in industry, these milestones can take the form of design reviews. A design review can become not just a check mark on the way to the vehicle, but also an opportunity to pull in alumni and local industry to showcase what the team has come up with (and gain more of the voice of experience). In the end, the advisor must make the team responsible for meeting these dates.

A Professional Organization (not just a car building club) - All of our campus clubs are associated with national professional organizations. In order to get the most out of the competition, it is important for the students to see how these fit into the profession as a whole. With limited advisor input in the past, vehicle teams have operated effectively without the professional side. They were completely organized and run by the students, even though most of the funding came from student fees. Recently, however, with two advisors on ASME and SAE, the professional sides of both organizations have improved. Both are among the largest in the west, and have received chapter awards. The more professional approach with advisor involvement has translated into more organized design teams.

Design Space - Design teams need space to work. One of the reasons designs may be inadequate is the students do not have a place to work on them. To combat this, a student project design office has been recently set up. In addition to a working space, it is intended to also encourage team continuity by providing a place to design — and to document and store - the team and vehicle history.

Shop Time - Whatever the method used for constructing the vehicle, the students must have sufficient access and sufficient supervision to safety build the components. A new technician at our student shop has been a great help to the clubs. Also, the shop has been updated and student technicians trained such that the teams can have more access. Late hour limits are still set for safety reasons.

Experience and Time - Students have limited skill sets and limited time. Forming a good team for a student design project is the students' responsibility, but the advisor can guide them. In our programs we have begun to explore a way to broaden the impact of our clubs on campus by drawing in students from other majors. Our teams have traditionally been closely tied to an 
academic department. Although we have had crossover from other majors it has not been institutionalized. This year we are making a concerted effort to involve other majors. We are calling on industrial and manufacturing engineers to help with planning and production, aerospace engineers to help with aerodynamic design and analysis, and industrial technologists to help with marketing plans if required by the competition (such as Mini-Baja). This multidisciplinary approach dovetails well with changes being made in our basic curriculum along the same lines.

Funds - Financial limitations are another important lesson for the students to learn. Seeking and obtaining funds and equipment can be a good networking experience for the students as well. However, too little funds can equal too much frustration with the project. The advisor can seek institutional methods to help support the teams. Our teams receive student fee money since they are an instructionally related activity. In addition, the students have access to our industrial advisory council members, who have been very generous to the teams. These activities are in addition to the donations they have obtained on their own.

Minimum GPA - Since some students may over-prioritize the team competition and let their coursework suffer, an easy change to implement is to require a minimum GPA for club participation. This approach worked in many athletic programs, although it can occasionally force grade inflation.

\section{Influence of competition rules}

Although the advisor has a significant role to play in ensuring the educational benefits mentioned above, a well-designed and well-executed competition is also essential. The competitions we have been involved with are among the best available for providing these learning experiences to our students. However, there are ways in which we feel these competitions could improve. This section summarizes some of the things that work well and some that may not.

Each of these competitions has a clearly defined set of rules, including the safety, performance, and limitations of the vehicles. The rules also allow some degree of flexibility in the achievement of the performance goals, obviously an important consideration for a design project. During competition, there are several performance evaluations, with relative importance identified in the rules (so students can focus on the critical goals). In addition, all competitions include a design presentation and report component, to ensure that student actually did engineer the vehicle and understand why things work. These competition features are important to ensuring a good experience for the students. However, there are a few areas that could be improved:

Development Time - The constraint of one year to develop a whole new vehicle, while not entirely unknown to industry, is still a major burden to place on students. Since the students perform this work in their spare time, they may learn to cut corners rather than putting in the time required to do the job right. If competitions could release rule changes 18-24 months ahead of time, rather than 10-11 months, advisors could encourage their teams to start work on the next design in parallel with completing the current year's vehicle. 
One-Year Vehicles - It is in an engineer's nature to want to create his/her own solution (with all of its unknown problems), rather than improving a known system. In industrial design, the latter is the better approach since it reduces cost and leads to improved quality. Unfortunately, with a one-year development cycle, a mandated minimum amount of the vehicle changed, and no second-year vehicles allowed, students might learn that it is important to change components each design cycle. Instead, they should learn to keep what works and focus their energy on the sub-optimal systems. These competitions should encourage - or at the very least, allowstudents to learn this first-hand. Perhaps an option is to allow both first-year and second-year cars at the competition, and have their scores compared separately.

Design Competition - Design judging is critically important to ensure that student learning is well directed. Innovation is of course an important part of design but rewarding innovation that does not translate into improved performance leads students to want to add glitz simply to gain design points. If a competition is arranged such that a team can consistently do well in design and not place well in the performance events the students are not learning that good design is inseparable from good performance. The design process is where much of the valuable learning occurs. Judges and judging schemes must keep this in mind to ensure that the students get the right message. If a vehicle sustains a mechanical failure in competition clearly the team loses points because they have not performed well in the event but this failure should also be reflected in the design scoring to cement the connection in the student's minds that the initiation of the failure was in the design.

Intermediate Milestones - When competitions are associated with professional organizations, there is an opportunity to distribute the judging work over time and space. For example, student designs should first be evaluated when completed, not just when the vehicle is built. Local sections of national organizations could hold a required design review day six months in advance of the competition. This would ensure all teams have complete designs in a timely manner. It would also encourage industry feedback to the teams earlier, when they can still change their direction.

Event Timing - For safety reasons, competition organizers need to carefully plan when and where the teams will meet. Quarter and Semester schools have exams at different times, and scheduling events around this time is detrimental to student performance. It can also affect driving safety, since students often are sleep-deprived at exam time. Competitions during the school year force students to hurry their driving to miss fewer classes. Competitions in early summer (after ALL schools are done with exams) might be better.

Organized Travel - When a team is forced to carry a large trailer over long distances, accident risk is increased. SAE competition organizers, since they involve larger vehicles and are associated with vehicle manufacturers, may be able to address some of our travel concerns. If several universities from a region are traveling to a competition, perhaps the competition organizers could help arrange joint transportation of all of the vehicles. For example, a vehicle transporter could pick up Formula SAE cars in an Atlanta parking lot two days before competition and deliver them all to the testing area. 


\section{Conclusion}

Student design competitions give engineering students an opportunity to put their coursework into practice, while creating something all their own. The involved students are typically passionate about the project, sometimes to the detriment of their classes. Although the benefits of these activities are great, there are some educational, student, and technical challenges to be managed as well. Competition organizers and advisors must find a way to ensure the best educational results for the students while alleviating safety concerns.

The advisor can influence the scope of the design, the project management, and other details. How much they influence the design can have a significant influence not only on the results at competition, but also on the experience gained by the students. In addition to directly advising the team, institutional changes may also be necessary. For example, to reduce the load on an individual advisor, we are experimenting with two-year design cycles and subsystem development using our senior capstone design class. Time will tell what improvements result.

The competition organizers establish the allowable development time, event timing, and design assessments. They may also want to consider implementing intermediate milestones, incrementally improved second-year vehicles, and joint travel arrangements.

\section{Bibliography}

1. Daniel F. Dolan, Michael Batchelder, Wayne B. Krause, Casey Allen, Chenoa Jensen, "Manufacturing and Design Education Through National Competitions.” 2001 ASEE Annual Conference.

2. Tonya L. Emerson, Russell S. Mills, "Student Chapters - An Adjunct to Engineering Education." 2003 ASEE Annual Conference, Paper \# 2003-1774.

3. Richard G. Golembiewski, "Managing Student Vehicle Projects: The Non-Technical Side." Published online at http://students.sae.org/competitions/managingprojects.pdf, October 2004.

4. Scott A. Miers, Carl L. Anderson, Paula F. Zenner, "Creating an Engineering Enterprise Team Based on the SAE Clean Snowmobile Challenge." 2002 ASEE Annual Conference, Paper \# 2002-1863.

5. Joseph J. Rencis, "The Formula SAE® Racecar Project at WPI." 2000 ASEE Annual Conference.

6. Giorgio Rizzoni, "Motorsports in the Engineering Curriculum at the Ohio State University." 1996 SAE Congress, Paper \# 962498.

7. Bijan Sepahpour, Shou-Rei Chang, "Valuable Lessons from the Successes and Failures of Teams of Engineering Students." 2003 ASEE Annual Conference, Paper \# 2005-2481.

8. Phillip C. Wankat, "Undergraduate Student Competitions." Journal of Engineering Education 94(3): 343-7, July 2005.

9. Paul W. Wickenden, Richard K. Stobart, "Integrating Formula SAE with the Engineering Curriculum." 2005 SAE Congress, Paper \# 2005-01-1796. 